\title{
O processo de validação de verdades matemáticas em sua historicidade
}

\section{The process of validating mathematical truths in their historicity}

\section{El proceso de validación de verdades matemáticas en su historicidad}

\begin{abstract}
Joel Gonçalves dos Santos Mestrando do Programa de Pós-Graduação em Educação Matemática (PPGEM), Universidade Estadual Paulista (Unesp), Instituto de Geociências e Ciências Exatas

Rio Claro, São Paulo, Brasil E-mail: joel.goncalves@unesp.br Orcid: 0000-0002-1987-3894
\end{abstract}

Fabiane Mondini Professora da Universidade Estadual Paulista (Unesp), Instituto de Ciência e Tecnologia - Câmpus de Sorocaba, e do Programa de Pós-Graduação em

Educação Matemática

(PPGEM)

Sorocaba, São Paulo, Brasil

E-mail: fabiane.mondini@unesp.br

Orcid: 0000-0003-4975-6637

Resumo: O texto tem por objetivo expor compreensões sobre o que vem a ser uma demonstração matemática, em sua historicidade. Como procedimentos metodológicos, pautamo-nos nas orientações expostas em trabalhos de Edmund Husserl (1859-1938). Trata-se de uma pesquisa de caráter qualitativo, desenvolvida segundo a abordagem fenomenológica. As discussões sobre as demonstrações ou verdades matemáticas são iniciadas com o modelo dedutivo, proposto por Euclides em Os Elementos, e são retomadas ao longo do tempo, por diferentes filosofias da matemática, que intencionavam estabelecer uma linguagem formal e livrar a matemática de suas contradições. O que definimos por matemática formal na atualidade é fruto desse processo.

Palavras-chave: Demonstração matemática. Prova. História e Historicidade. 
Abstract: The text aims to expose understandings of what is a mathematical demonstration, in its historicity. As methodological procedures we are guided by the guidelines exposed in works by Edmund Husserl (1859-1938). It's a qualitative research, developed according to the phenomenological approach. Discussions about mathematical statements or truths begin with the deductive model proposed by Euclides in Os Elements and are resumed over time by different philosophies of mathematics, which intended to establish a formal language and free mathematics from its contradictions. What we define by formal mathematics today is the result of this process.

Keywords: Mathematical demonstration. Proof. History and Historicity.

Resumen: El texto tiene como objetivo exponer la comprensión de lo que es una demostración matemática, en su historicidad. Como procedimientos metodológicos nos guiamos por las pautas expuestas en los trabajos de Edmund Husserl (1859-1938). Es una investigación cualitativa, desarrollada según el enfoque fenomenológico. Las discusiones sobre enunciados o verdades matemáticas comienzan con el modelo deductivo propuesto por Euclides en Os Elements y son retomadas a lo largo del tiempo por diferentes filosofías de las matemáticas, que pretendían establecer un lenguaje formal y liberar a las matemáticas de sus contradicciones. Lo que hoy definimos por matemáticas formales es el resultado de este proceso.

Palabras clave: Demostración matemática. Prueba. Historia e historicidad.

Recebido em 20/01/2021

Aceito em

21/02/2021 


\section{CONSIDERAÇÕES INICIAIS}

Intencionamos, com esse texto, compreender como as demonstrações matemáticas, bem como o modelo dedutivo, proposto por Euclides em Os Elementos, fazem-se presentes em cada época da História da Matemática, perfazendo-se, nesse sentido, uma tendência ${ }^{1}$ na validação de verdades matemáticas. Norteados pela interrogação: "O que é uma demonstração matemática em sua historicidade?", desenvolvemos um estudo teórico, com a intenção de expor compreensões filosóficas, históricas e teóricas relativas aos modos de validar a produção de conhecimento nessa Ciência.

O fazer matemático é reconhecido desde a antiguidade. Na pré-história, quando da necessidade imposta pelo meio físico e pelo crescimento populacional, o homem desenvolveu técnicas de plantio, de irrigação, de construções, entre outras que, no seu processo de elaboração e de concepção, estimulavam as relações de contagem e de mensuração, procedimentos próprios da matemática ${ }^{2}$.

É interessante notar que tal desenvolvimento matemático aconteceu, na maioria das vezes, por meio de descobertas espontâneas, que na observação e no teste de hipóteses se faziam válidas e, podemos por assim dizer, que tinham caráter prático e, portanto, apreensível pela comunidade. Entretanto, cada comunidade tem seu modo próprio de conceber e desenvolver ciência.

Compreendemos que "diferentes culturas têm diferentes maneiras de lidar com situações e problemas do cotidiano e de dar explicações sobre fatos e fenômenos naturais e sociais" (D'Ambrosio, 2018, p. 189). Com isso, entende-se também que o fazer matemático, não raras vezes, é expresso de maneiras distintas no entremeio das várias culturas antigas.

\footnotetext{
1 "Entende-se por Tendência todo impulso habitual e constante para a ação. Nisso a T. distingue-se do impulso, que é a ação súbita e temporária" (Abbagnano, 2007, p. 948).

2 Como a matemática mais antiga, "aquela resultante dos primeiros esforços do homem para sistematizar os conceitos de grandeza, forma e número, [...] focalizando de início o surgimento no homem primitivo do conceito de número e do processo de contar" (Eves, 2004, p. 25).
} 


\section{Universidade Federal da Grande Dourados}

De acordo com D'Ambrosio (2018), surge, deste modo, uma das questões mais intrigantes para os etnógrafos, antropólogos, linguistas, neurocientistas e, naturalmente, para os historiadores e educadores: Como são e como se originaram esses diferentes modos do fazer matemático? Enquanto educadores e com a intenção de contribuir com discussões que existem na comunidade acadêmica sobre o assunto, esclarecemos que neste texto voltamos nosso olhar para a matemática adjetivada de acadêmica e/ou formal.

A Matemática Acadêmica, que é universalmente praticada nos institutos de pesquisa e nos sistemas educacionais, é uma categoria ampla de conhecimento, uma construção abstrata originada nas culturas da bacia do Mediterrâneo e da Mesopotâmia (Iraque antigo) e das civilizações do vale do Nilo. Podemos dizer que a Matemática Acadêmica (e, portanto, a Matemática Escolar) tem como origem a Etnomatemática dessa ampla região ao redor do Mediterrâneo. Essa construção abstrata, muitas vezes chamada o estilo euclidiano, é baseada na lógica do tertium non datur. O estilo euclidiano é o protótipo de rigor matemático (D’ambrosio, 2018, p. 191).

Não é uma tarefa simples compreender as causas e circunstâncias que, como se observa nos tratados históricos, desencadearam uma matemática tão expressivamente rigorosa. Por algum motivo, "os processos empíricos do Oriente Antigo, suficientes o bastante para responder questões na forma de como, não mais bastava para as indagações mais científicas na forma por quê" (Eves, 2004, p. 94). Parece ter sido de súbito que uma "faísca de genialidade alterou o modo de pensar. Disso resultou não bastar mais ver para crer! Para CRER era preciso PROVAR. O mundo sensível era mutável e ilusório" (Bicudo, 1999, p. 118).

\section{Procedimentos Metodológicos}

Optamos por nos guiar nos procedimentos de análise da fenomenologia, principalmente nas orientações expostas no artigo 'Sobre história e historicidade em Edmund Husserl' (Bicudo, 2016). Bicudo (2016), com o objetivo de situar a visão husserliana a respeito do que vem a ser História e Historicidade, começa por argumentar em seu ensaio sobre as questões que levaram o autor a discutir essa 
temática. Husserl da indicativos de que há uma imersão das ciências ditas do espírito 3 e, portanto, da História, em procedimentos das ciências naturais. Há, por assim dizer, uma perda com o sentido e com a fundamentação requerida em tais ciências.

Ao tomar o espaço geométrico, tal como presente na obra de Euclides, portanto idealizado, Galileu cria um modo de proceder, então inédito, para trabalhar com a física, pois os objetos dessa ciência passam a ser estudados no espaço "idealmente exato", o que significa que já não estão sujeitos às facticidades do mundo sensível. A exatidão, assim obtida, é dada como objetivação, ou seja, como um espaço objetivo e exato, visto como perfeito para obter-se conhecimento objetivo e seguro. Instala-se, desse modo, um racionalismo que vem a sustentar os métodos investigativos de todas as ciências naturais. Essa visão racionalista se amplia, estendendo-se para uma visão naturalista formatando uma concepção de naturalidade das ciências (Bicudo, 2016, p. 24).

É no 'A Crise das Ciência Europeias', em 1970, que o filósofo expõe suas críticas no que diz respeito à "matematização" da natureza. Mas então, como Husserl se desvencilha da crise causada pelas investigações que acabam por proceder como nas ciências naturais, "que tomam para estudo a experiência ingênua, naturalizada e tida como objetivamente dada?" (Bicudo, 2016, p. 25).

Husserl intenciona uma história que busque pela "origem" e não aquela que se atém ao relato do desenvolvimento e encadeamento dos fatos "históricos". E vai além da busca pela origem, preocupando-se em mostrar como o evidenciado na origem se enrola em compreensões e expressões/compreensões entre sujeitos, que, pela linguagem e pela tradição vai se mantendo presente ao mundo histórico-cultural, que, também, pode ser entendido como o mundo do a priori histórico onde vivemos na circunvizinha do que aí está como dado (Bicudo, 2016, p. 32).

As concepções de História e Historicidade presentes nos trabalhos de Husserl, bem como os aspectos metodológicos da investigação histórica concebida por ele, ao

\footnotetext{
${ }^{3}$ Nossa compreensão se dá como em Gadamer (2002b), que entende que as ciências do espírito compreendem a si mesmas por analogias à ciência da natureza. "Como se sabe, o termo tornou-se popular especialmente por meio de Dilthey. Mas Dilthey nunca esteve satisfeito com o termo. Uma vez ele riscou em um manuscrito a palavra 'ciências do espírito' e a substituiu por ciências histórico-sociais. [...] quem por exemplo, prefere dizer ciências humanas, precisa excluir expressamente a medicina" (Scholtz, 1988, p. 320).
} 
investigar fenomenologicamente aquilo que é dado no presente, empregam-se num processo retrospectivo, utilizando-se das ideias nucleares presentes na ciência que se está tomando como foco da pesquisa. Desta forma,

É como se estivéssemos olhando-a e nos locomovendo em sua superfície, aquela do momento do "agora" em que olhamos interrogadoramente para isso que nos é dado. Assumindo a postura de inquirir intencionalmente, locomovemonos para o mais profundo, ou seja, para um agora que se afasta deste, e vamos desnudando camadas de atos sensoriais, psicológicos e espirituais que vieram constituindo esta ciência, tal como nos é dada no presente (Bicudo, 2016, p. 37).

Parte-se do presente, num entrelaçamento tanto do passado quanto do futuro: "Isso significa que nos locomovemos em um horizonte histórico e que, entretanto, podemos, intencionalmente, investigar sua estrutura essencial de modo metódico" (Bicudo, 2016, p. 37-38), ao mesmo tempo em que pro-jetamos ${ }^{4}$ o futuro.

Para ele, "ambos - intropatia ${ }^{5}$ (Einfühlung) e linguagem - são nucleares à comunicação entre sujeitos e, desse modo, à constituição da esfera da intersubjetividade" (Bicudo, 2016, p. 39). Ou seja, intropatia e linguagem são nucleares para com a condução e a manutenção do que se constitui a tradição ${ }^{6}$, e nesse sentido, estão presentes para a história. No momento em que ela é posta como tema, tanto a intropatia quanto a linguagem se constituem em material para a investigação daquilo que configura os atos originais.

\footnotetext{
4 "Em geral, a antecipação de possibilidades: qualquer previsão, predição, predisposição, plano, ordenação, predeterminaçâo, etc., bem como o modo de ser ou de agir próprio de quem recorre a possibilidades. Neste sentido, na filosofia existencialista, o P. é a maneira de ser constitutiva do homem ou, como diz Heidegger (que introduziu a noção), sua 'constituição ontológica existencial'” (Abbagnano, 2007, p. 800).

5 "A intropatia é basicamente conhecimento do outro que se desenvolve nas vivências em que o outro é dado (trazido, exposto) ao eu em sua corporeidade. É uma percepção constituinte da intersubjetividade. Não se trata, assim, de um conceito teórico ou de uma afirmação predicativamente construída" (Bicudo, 2016, p. 39-40).

6 Tradição é aqui compreendida como Dasein, termo alemão utilizado por Heidegger para dizer do homem lançado em sua temporalidade, em sua condição histórica, "na qual toda compreensão é possibilitada e ao mesmo tempo limitada pela história e pela finitude" (Heidegger, 1988). "Quando se nega a história efeitual na ingenuidade da fé metodológica, o resultado pode até ser uma deformação do próprio conhecimento" (Gadamer, 2002a, p. 450).
} 


\section{Universidade Federal da Grande Dourados}

História assim compreendida "não significa apenas o passado no sentido do que passou, mas também a sua proveniência. O que tem história encontra-se inserido num devir. O seu desenvolvimento pode ser ora ascensão, ora queda" (Gadamer, 2002a, p. 470). Sendo assim, História é "um conjunto de acontecimentos e influências que atravessam passado, presente e futuro. É o que se move 'no tempo'. São as transformações dos destinos dos homens, dos grupos humanos e de suas culturas" (Gadamer, 2002a, p. 470). Assim, não se partiu de métodos prévios e nem de referenciais teóricos predeterminados, mas se iniciou com os fenômenos das "demonstrações matemáticas" e do "modelo dedutivo de Euclides", tal qual eles se mostram a nós: nos documentos, nos artigos, nas teses e nas compreensões de pesquisadores que se dedicaram ao estudo do assunto.

\section{A VALIDAÇÃO MATEMÁTICA EM RETROSPECTIVA}

As demonstrações ou provas em matemática são artifícios utilizados com o objetivo, a priori, de validar afirmações expressas por propriedades numa teoria com convicção, com verdade e com consistência7 ${ }^{7}$ Em outras palavras, Garnica (1995), em sua tese de doutorado, diz que uma demonstração "é o que atesta a veracidade ou autenticidade, a garantia, o testemunho, o processo de verificação da exatidão de cálculos ou raciocínios, a dedução que mantém a verdade de sua conclusão apoiando-se em premissas admitidas como verdadeiras" (Garnica, 1995, p.10). Entretanto, o emprego sistemático desses artifícios não está limitado a apenas justificar ou verificar se um determinado fato é verdadeiro ou falso. Silva (2002) argumenta que as demonstrações matemáticas possuem como características alguns aspectos interessantes em suas estruturas, são eles: o lógico-epistemológico, o retórico e o heurístico. Em suas palavras:

Chamarei de lógico-epistemológico esse aspecto das demonstrações que as mostra como objetos lógicos ideais, árvores ou sequências ordenadas no espaço lógico, segundo relações de dependência, ou consequência, lógica. E de retórico

\footnotetext{
7 Muitas vezes esse caminho também é um meio de indução à descoberta matemática.
} 
o aspecto das demonstrações, segundo o qual, elas aparecem como portadoras de força coercitiva de aquiescência às teses demonstradas. Há ainda um aspecto a ser considerado. Demonstrações podem ter também uma função heurística. Isto é, elas podem ser indutoras de descoberta matemática (Silva, 2002, p. 69).

O autor refere-se a uma demonstração matematicamente perfeita como sendo uma junção desses fatores, ou seja, ela é "logicamente correta, compreensível a um agente racional com limitações cognitivas humanas e, ainda assim, heuristicamente estimulante" (Silva, 2002, p. 71). Nesse sentido, entende-se que uma demonstração perfeita é aquela em que a riqueza heurística deve ser acessível a quem for se utilizar dela, levando em consideração que todos somos limitados cognitivamente. Mas só com essas palavras não fica esclarecido, em detalhes, como são expressos esses artifícios e nem se há uma estrutura toda definida e generalizada por trás de tudo.

Em Bicudo (2002), o uso sistemático de demonstrações ocorre com frequência, e é exposto com todas as suas características, por intermédio do que os matemáticos chamam de sistema formal, que é a parte sintática de um sistema axiomático. Tais sistemas são descritos e compostos por três partes essenciais. Destaca-se, a princípio, a linguagem, a qual diz respeito aos símbolos e expressões empregadas. Toda expressão é um conjunto de símbolos logicamente dispostos e, ao mesmo tempo, um conjunto de expressões que decorre do que se denomina uma fórmula da linguagem. A parte seguinte é descrita pelos axiomas, que perfazem as afirmações primeiras em uma dada teoria, ou seja, são as condições iniciais. Todo axioma é também uma fórmula de linguagem. A terceira e última parte é composta e caracterizada pelas regras de inferência, que são os modos pelos quais se pode afirmar que, em determinadas condições, uma fórmula pode ou não ser deduzida.

O mesmo autor deixa claro que, em sistemas axiomáticos, "demonstrar uma proposição (exprimindo uma propriedade de um conceito) significa argumentar pela aceitação de sua validade, a partir da validade de outras proposições já demonstradas" (Bicudo, 2002, p. 80). As fórmulas que são deduzidas a partir de outras anteriormente determinadas são chamadas de conclusão (tese) da regra. Já aquelas 


\section{Universidade Federal da Grande Dourados}

utilizadas no processo dedutivo, e que dão "certeza" à argumentação demonstrativa, são as hipóteses. Fica assim estabelecido o princípio de consistência em teorias sistematizadas. Pode-se entendê-las como integradas, no sentido de dependência entre as afirmações, visto que cada nova dedução depende da anterior. Nesse viés de análise, demonstrar é argumentar a partir de proposições já determinadas anteriormente, além de ser um modo com o qual, no entrelaçamento lógico, atinge-se a verdade incontestável, consistente.

\section{AS DEMONSTRAÇÕES EM TEMPOS REMOTOS}

Quando tentamos identificar, no entremeio dos processos da História da Matemática, a origem das demonstrações e seus modos de exposição, sua gênese e seus significados, os estudos nos remetem a tempos antigos - por volta do século $\mathrm{V}$ a. C., quando o desenvolvimento matemático ocorria de forma natural por meio de técnicas e processos práticos que participavam de um objetivo comum entre as sociedades da época: o de possibilitar destreza aos afazeres que diariamente se impunham perante a vida. Seja para contar rebanhos ou para construir monumentos de engenharia, nessas vivências, estava o conhecimento matemático. Duas nações são as mais comentadas na literatura acadêmica quando se abre a discussão sobre as origens das verdades matemáticas - a egípcia e a babilônica - pois, além de terem sido duas potências econômicas, a elas são concedidos os créditos de diversas descobertas matemáticas (Eves, 2004).

Porém, a hegemonia mundial é momentânea, e com o passar dos anos "algumas civilizações desapareceram, o poder do Egito e da Babilônia declinou, e outros povos, especialmente os hebreus, os assírios, os fenícios e os gregos, passaram ao primeiro plano" (Eves, 2004, p. 94). Mas não foi só a ascensão dessas civilizações que se tornou evidente. Seus modos de vida, como é de praxe acontecer com países em alta, foram também se destacando. Com todas as mudanças ocorridas, houve, em algum momento, questionamentos que se direcionavam às ciências. Na matemática, o questionamento foi sobre a veracidade dos artifícios e 


\section{Universidade Federal da Grande Dourados}

nisso aconteceu, pela primeira vez, a análise de suas bases fundadoras e as primeiras verificações que garantiriam as verdades, ou falsidades, dos fatos matemáticos (Eves, 2004).

Ressalta-se que nas produções que vinham sendo realizadas, até então, não se via traços e nem semelhanças com os processos de verificação matemática. Em heranças deixadas por elas não se identifica "o caráter sistemático, rigoroso, puro isto é, não empírico - e, em grande medida, a indiferença com respeito a aplicações práticas imediatas que caracterizam o conhecimento matemático, tal como o entendemos hoje" (Silva, 2007, p. 31). Mas, se por um lado esses povos não buscavam justificar os fatos que eram descobertos, por outro eles desvendavam suas possíveis aplicações e lançavam as pedras fundamentais que mais tarde seriam estudadas e demonstradas, e o foram. Como exemplo, podemos citar o famoso teorema de Pitágoras $^{8}$, que certamente fazia parte da matemática babilônica. Contudo, este teorema só obteve sua demonstração formal anos mais tarde, o que veio garantir a verdade de seu enunciado.

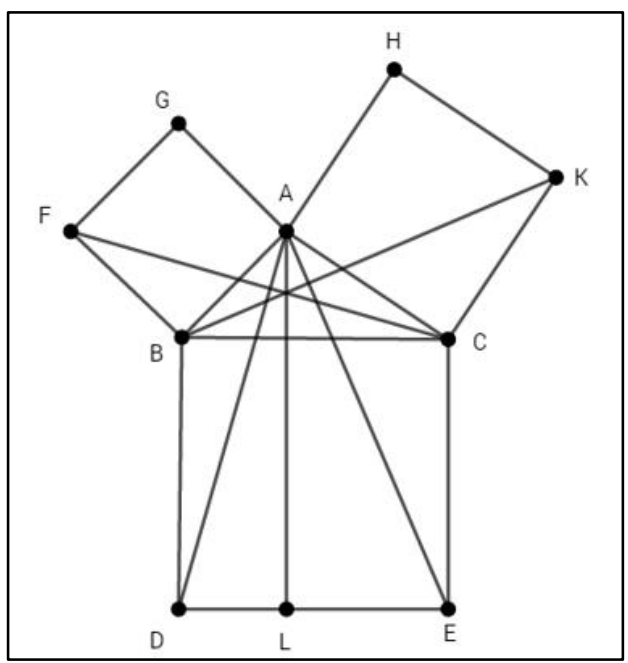

Figura 1. Representação da construção de apoio para a demonstração do teorema de Pitágoras.

Fonte: Construção adaptada de (Euclides, 2009, p. 133). 8 "Nos triângulos retângulos, o quadrado sobre o lado que se estende sob o ângulo reto é igual aos
quadrados sobre os lados que contêm o ângulo reto" (Euclides, 2009, p. 133). 
Assim, podemos afirmar que demonstrações matemáticas são "invenções gregas e caracterizam a matemática produzida por essa civilização" (Silva, 2007, p. 31). É unanime entre os historiadores que entre os documentos que dizem respeito à origem da matemática antiga, o mais importante é o Sumário Eudemiano de Próclo. De acordo com Eves (2004), essa é principal fonte de estudos a respeito do desenvolvimento da matemática grega, no qual o escritor apresenta um resumo acerca da geometria, descrevendo desde as primeiras produções matemáticas realizadas por esta civilização até os dias de Euclides, quando este organiza em 13 livros o que comumente chamamos de Os elementos de Euclides (c. 300 a.C.). Ainda em acordo com o Sumário Eudemiano, Tales de Mileto foi o primeiro homem a demonstrar uma verdade matemática. Alguns de seus resultados são recorrentes na geometria:

1.Qualquer diâmetro efetua a bissecção do círculo em que é traçado.

2.Os ângulos da base de um triângulo isósceles são iguais.

3.Ângulos opostos pelo vértice são iguais.

4.Se dois triângulos têm dois ângulos e um lado cada um deles respectivamente iguais, então esses triângulos são iguais.

5.Um ângulo inscrito num semicírculo é reto (Eves, 2004, p. 95).

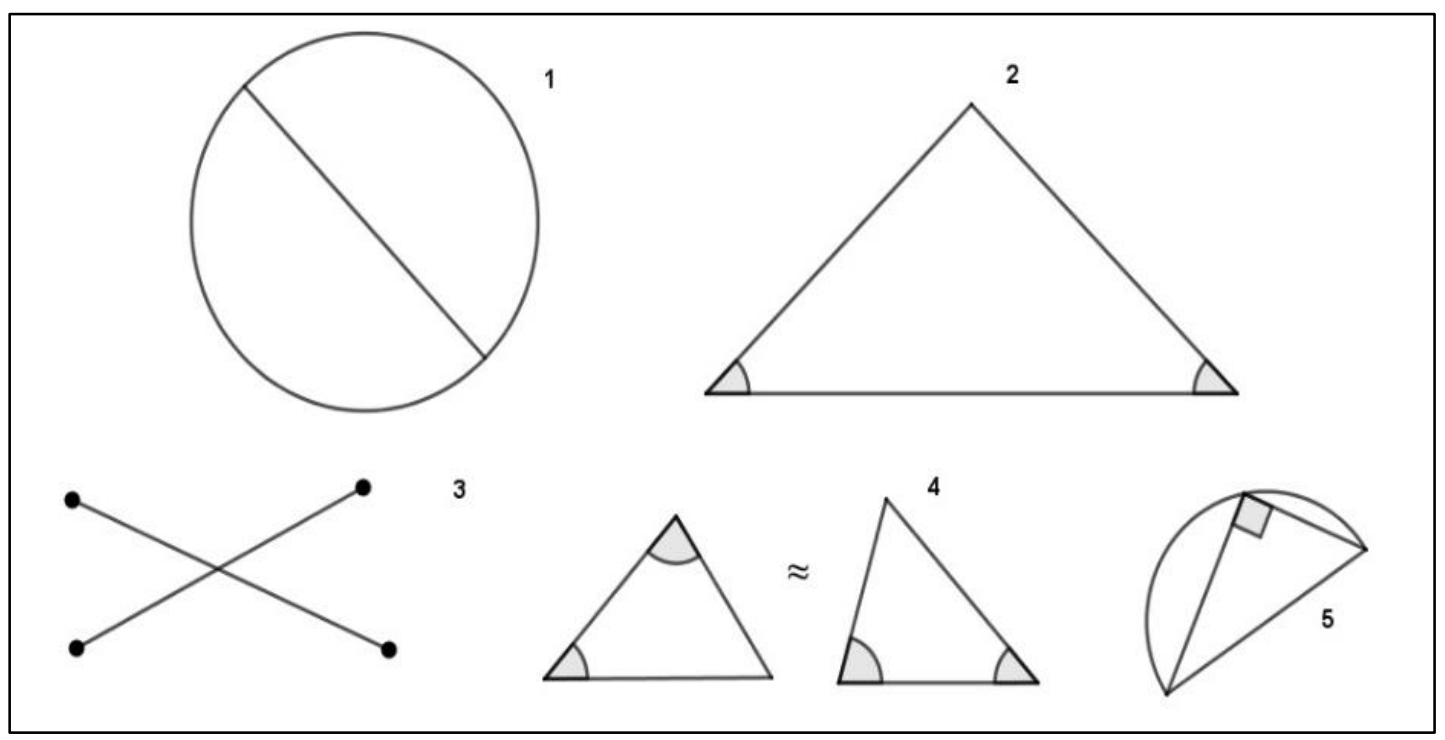

Figura 2. Representação dos resultados encontrados por Tales.

Fonte: Elaborada pelos autores. 
Outro matemático citado na obra foi Pitágoras, que nasceu por volta de 572 a. C. na ilha egeia de Samos. Pouca coisa se sabe a respeito da vida dele, "mas a tradição pitagórica sobreviveu ao seu fundador e influenciou de modo inequívoco o pensamento e a ciência ocidentais" (Silva, 2007, p. 32). Em Crotona, ele funda a escola pitagórica, "uma seita mística na qual conviviam o racionalismo grego e os elementos do pensamento mágico de povos mais ao leste e ao sul” (Silva, 2007, p. 32). Não se tratou de um centro de estudos puramente matemático; os registros indicam que lá ocorriam também estudos de caráter filosófico e os concernentes às ciências naturais. Os pitagóricos são conhecidos pela sua "teoria, meio metafísica, meio mágica, que tudo se reduz a números" (Silva, 2007, p. 32). Acredita-se que a teoria dos números tenha começado a se desenvolver nesse meio em que a filosofia da escola estava em vigor.

Mas mesmo que esses matemáticos tenham resistido ao tempo e sejam lembrados por seus resultados, é a obra Os Elementos de Euclides que mais destacada desse período histórico. A sua estrutura apresenta a demonstração de 465 proposições. Cópias da obra chegaram até nós através de traduções árabes, que no século XII passaram a ser traduzidas para o latim e, mais tarde, no século XVI, para o vernáculo. A grande obra teve sua primeira versão impressa em 1482, em Veneza, constituindo um dos primeiros livros de matemática impressos; calcula-se que, desde então, pelo menos mil edições foram publicadas — talvez, o livro de maiores edições além da Bíblia. Certamente nenhuma obra matemática teve influência comparável à de Os Elementos.

\section{NO MEDIEVO}

Durante os tempos de Euclides, a cidade de Alexandria era o centro das atividades intelectuais do mundo dito civilizado. Entretanto, em função de seu destaque, ela passa a sofrer ameaças de exércitos estrangeiros. De acordo com Singh 
(2014), a cidade sofre seu primeiro ataque no ano 47 a. C. por Júlio César ${ }^{9}$, quando este tenta derrubar Cleópatra ${ }^{10}$ ateando fogo em seu exército. A biblioteca, que ficava perto do porto, acabou também sendo incendiada, o que levou à perda de milhares de livros ${ }^{11}$.

Além disso, no ano 389, a biblioteca sofre outro ataque, desta vez por cristãos. O imperador Teodósio deu ordens ao bispo Teófilo de Alexandria para destruir todos os monumentos pagãos.

E assim a Biblioteca foi jogada no meio da fúria para a destruição de ícones e altares. Os estudiosos "pagãos" tentaram salvar seis séculos de conhecimento, mas antes que pudessem fazer qualquer coisa foram linchados pela horda de cristão. O mergulho em direção à Idade das Trevas tinha começado (Singh, 2014, p. 72).

Porém, algumas cópias escaparam e, assim, os estudiosos continuaram a visitar a cidade de Alexandria em busca de conhecimentos. Entretanto, outro ataque em 642, agora desferido pelos muçulmanos, veio terminar o que os cristãos começaram.

Quando Ihe perguntaram o que devia ser feito com a biblioteca, o califa Omar, vitorioso, declarou que os livros que fossem contrários ao Corão deveriam ser destruídos. E os livros que apoiassem o Corão seriam supérfluos e, portanto, também deviam ser destruídos. Os manuscritos foram usados como combustível para as fornalhas que aqueciam os banhos públicos. A matemática grega virou fumaça (Singh, 2014, p. 72).

No período que segue, compreendido entre os anos de 476 d. C. e 1500 d. C., mais comumente identificado como a Idade Média, outras nações passaram a ganhar espaços na dinâmica econômica emergente, e os centros de estudos matemáticos da antiguidade, no entremeio de todos os acontecimentos, perderam seu vigor e

\footnotetext{
${ }^{9}$ Caio Júlio César foi um patrício, líder militar e político romano. Desempenhou um papel crítico na transformação da República Romana no Império Romano.

${ }^{10}$ Cleópatra foi a última rainha da dinastia de Ptolemeu, general que governou o Egito após a conquista daquele país pelo rei Alexandre III da Macedônia.

11 Porém, a rainha, apreciadora da importância do conhecimento, resolveu restaurá-la.
} 


\section{Universidade Federal da Grande Dourados}

acabaram por desaparecer. Ao sair da Grécia Antiga - a tão aclamada Grécia de Sócrates, Platão, Aristóteles e companhia —, a matemática volta a desabrochar, mesmo que sob outro enfoque, nos mundos árabes e hindus. Em comparação aos gregos, esses povos não se preocuparam, a princípio, com o modelo dedutivo euclidiano. Porém, mesmo sem interesses pelas demonstrações matemáticas, preservaram as obras que restaram da destruição ocorrida nas bibliotecas da época e iniciaram um processo de cópia e restauração dos livros, recriando alguns teoremas que haviam se perdido.

Nessa recriação, eles são agraciados por terem inserido novos elementos na matemática, sendo o zero o seu trunfo máximo. Com seu uso, por exemplo, é possível distinguir 33 de 303, em um sistema numérico posicional, além de demarcar a posição vazia, entre outras funções.

Os hindus reconheceram que o zero tinha uma existência independente, além do mero papel de marcar espaços entre números. O zero era um número como os outros, ele representava a quantificação do nada. E pela primeira vez o conceito abstrato do nada recebia uma representação simbólica (Singh, 2014, p. 73).

Assim, a partir do que restou de Alexandria, a Índia e a Arábia produziram e deram solidez ao conhecimento numérico que conseguiam estruturar, construindo uma linguagem nova e mais eloquente para o conhecimento matemático, dando origem ao sistema hindu-arábico. "As ideias de Pitágoras e Euclides não eram menos elegantes em seu modo de expressão desajeitado. Mas traduzidas para os símbolos da Arábia desabrochariam e produziriam conceitos novos e mais ricos" (Singh, 2014, p. 72).

\section{IDADE MODERNA}

No período consagrado como Idade Moderna, as teorias matemáticas já haviam sido, em grande parte, modificadas em seus conteúdos, métodos e, como bem citou Silva (2007), em espírito. A álgebra, que até então não havia entrado em cena, 


\section{Universidade Federal da Grande Dourados}

surgiu. Para Silva (2007), "o que mais chama atenção nessa época são a crescente autonomia do simbolismo matemático e as novas concepções de número germinadas nos domínios da álgebra" (Silva, 2007, p. 77). Passamos a uma nova fase da história da matemática marcada fortemente por símbolos e expressões algébricas. Desde a Antiguidade, a partir de Diofanto ${ }^{12}$, e mais tarde com os algebristas árabes, na Idade Média, tem-se um grande desenvolvimento e inserção de notações algébricas na matemática. Tal inserção possibilitou a constituição de um sistema simbólico, "capaz de expressar em sinais os termos numéricos (incógnitas e parâmetros) e as operações às quais as quantidades denotadas por esses termos estão submetidas" (Silva, 2007, p. 77).

Outra consequência devido à sofisticação e inserção de símbolos algébricos é a resolução de equações que, com os famosos algebristas Scipione del Ferro (14651526), Tartaglia (1499-1557), Cardano (1501-1576) e Bombelli (1526-1572), progride chegando às técnicas mais elevadas para a época. Até então, a resolução de equações consistia em preenchimento $^{13}$ e balanceamento ${ }^{14}$. Em suma, os matemáticos italianos inventaram alguns métodos que reduzem equações a suas formas canônicas, possibilitando assim a expressão das raízes dessas equações canônicas através de operações com seus coeficientes. "Desse modo, o procedimento de resolução de equações torna-se pouco a pouco um processo mecânico de manipulação de símbolos. Estão criadas as condições para que o simbolismo algébrico adquira uma espécie de vida própria, gerando os seus próprios conceitos" (Silva, 2007, p. 78).

Nesse sentido, e com o avanço dos estudos de equações, muitos resultados foram facilmente concebidos. Entretanto, vez ou outra, os matemáticos esbarravam em expressões que para aquela época não faziam muito sentido. A raiz quadrada de números negativos é talvez um dos maiores exemplos. Esse mesmo problema foi

\footnotetext{
${ }^{12}$ Nascido entre os anos 201 e 214 e falecido entre 284 e 298, Diofanto é considerado o maior algebrista da antiguidade, e desempenhou um papel semelhante ao de Euclides em sua obra de Geometria.

${ }^{13}$ Consiste na eliminação dos termos a serem subtraídos de um membro da equação por adição a ambos os membros de termos iguais.

${ }^{14}$ Consiste na redução de termos iguais de ambos os membros de uma equação.
} 
estudado por Bombelli e Cardano dando origem à concepção de números imaginários. Silva (2007), em suas análises, diz que este foi um dos momentos mais importantes para a história da matemática, não só em respeito à extensão do conceito de número, mas também para a constituição da concepção moderna de matemática.

Nesse ato aparentemente banal em que o simbolismo matemático clama pela sua autonomia são criados números que não mais correspondem a uma particularização do conceito de quantidade, mas respondem apenas à razão formal. Se um termo numérico se comportava como se denotasse um número, mesmo que isso fosse impossível segundo a concepção de número em voga, então ele efetivamente denotava um número. Desde então números não são mais entidades independentes apenas denotadas pelos símbolos, mas entidades geradas pelo próprio simbolismo que se caracterizam exclusivamente pelas suas relações operatórias com outros números (Silva, 2007, p. 78-79).

Isso nos trouxe a possibilidade de extensão dos domínios matemáticos, acrescentando a ele novos objetos, como o fez Bombelli com os números imaginários. Assim, iniciava-se na álgebra desse episódio histórico a concepção formal do fazer matemático. Acaba-se por entender que a matemática pode ser pensada como sendo "estruturas ou invólucros formais de possíveis domínios de objetos, definidos por relações puramente formais no interior de um sistema simbólico" (Silva, 2007, p. 80).

No decorrer dos anos, no século XVII, ressalta-se algumas revoluções referentes à Matemática. Destaca-se o desenvolvimento da matemática moderna com Cavalieri (1598-1647), Descartes e Leibniz (1646-1716), entre outros mais. A característica marcante é o uso de métodos infinitários ${ }^{15} \mathrm{em}$ aritmética, álgebra e geometria, o que possibilitou também a criação do cálculo infinitesimal por Newton (1643-1727) e Leibniz, e a "algebrização" da geometria por Descartes. A vantagem de se trabalhar com os métodos infinitários é o não uso da dupla redução ao absurdo, mesmo que sem o rigor requerido na matemática de Arquimedes.

Se esses métodos não têm o rigor da matemática de Arquimedes [...], têm ao menos a vantagem de evitar a dupla redução ao absurdo que o método

\footnotetext{
15 Método da matemática clássica que busca abstrações sobre o infinito "das demonstrações não construtivas, dos objectos ideais, é uma extensão conservativa da matemática finitista” (Oliveira, 2005).
} 


\section{Universidade Federal da Grande Dourados}

arquimediano de exaustão exige, privilegiando demonstrações explicativas, ou causais, segundo os preceitos lógicos-epistemológicos de Aristóteles (Silva, 2007, p. 81).

A grande conquista para a Idade Moderna foi o cálculo criado por Leibniz e Newton de forma simultânea e independente. Leibniz publicou a sua descoberta em um texto de seis páginas em 1684 sob o título: Um novo método para máximos e mínimos, assim como para tangentes, que não é obstruído por quantidades irracionais e fracionárias, e um cálculo notável para eles ${ }^{16}$. Silva (2007) destaca que as demonstrações matemáticas presentes no texto aparecem de forma obscura. Já Newton publicou seu método de cálculo infinitesimal entre 1704 e 1736, mas provavelmente o escreveu entre 1655 e 1666. Mesmo com obras tão elevadas,

ambos foram acidamente criticados pelo caráter vago e pouco rigoroso de suas criações. Newton, por Berkeley e Leibniz pelo holandês Nieuwentijt (se bem que, no segundo caso, a disputa não envolvesse uma negação pura e simples do método, mas antes as idiossincrasias próprias de cada um no trato com os infinitésimos) (Silva, 2007, p. 82).

O cálculo só obteve sua fundamentação rigorosa no século XIX, com a noção de limite e a redução dessa noção às puramente aritméticas, o que elimina as quantidades infinitesimais e métodos pouco rigorosos de aproximação. O que faltava, nesse sentido, era a criação de uma teoria dos números que possibilitasse a resolução de alguns problemas. Como ilustração cita-se, "por exemplo, a natureza dos números irracionais - que se arrastava, a bem da verdade, desde a descoberta das grandezas incomensuráveis no século $\mathrm{V}$ a. C" (Silva, 2007, p. 82). Em resumo, mesmo que o cálculo tenha tido sucesso em sua criação, ele não foi tão bem recebido, por ser uma teoria que deixava a desejar do ponto de vista lógico.

Ainda outro importante teórico e filósofo em matemática, como citado anteriormente, que no século XVII tornou-se um marco fundamental, foi René

${ }^{16}$ Nova methodus pro maximis et minimis, itemque tangentibus, quae nec fractas nec irrationales quantitates moratur, et singulare pro illis calculi genus. 


\section{Universidade Federal da Grande Dourados}

Descartes. A sua obra A Geométrie, publicada em 1637 em forma de apêndice ao Discours de la Méthode, atesta o sucesso de seus métodos.

Ele cria um método original para tratar a matemática tradicional herdada dos antigos gregos, não mais se restringindo a termos exclusivamente geométricos, como o faziam. "Números, para eles, estavam sempre associados a segmentos, e operações aritméticas, como somas e produtos a construções geométricas" (Silva, 2007, p. 85). O quadrado de um número, nesse contexto, podia ser associado à área de um quadrado; o cubo, por sua vez, associado ao volume. Mas, isso acabava por suscitar outros problemas quando o expoente ia crescendo e se tornava maior do que 3. Quando Descartes trata desse problema, ele representa as operações algébricas por operações apenas sobre os segmentos, e não mais como figuras de dimensões superiores como faziam os gregos. Isto é, para ele, operações com números em segmento só poderiam resultar em números em segmentos.

Assim, na resolução de um problema geométrico, Descartes estava livre para tratar os segmentos dados como constantes, os segmentos a serem obtidos como incógnitas e relacioná-los por meio de identidades geométrica conhecidas, dando origem, desse modo, a uma relação funcional entre constantes e incógnitas - em suma, uma equação. Bastava então, para resolver o problema geométrico, resolver a equação algébrica - isto é, isolar as incógnitas em termos das constantes - e, depois, construir os segmentos correspondentes às grandezas antes incógnitas, mas agora dadas em razão das grandezas conhecidas (Silva, 2007, p. 85).

Por fim e sob o amparo das análises desse período, conclui-se que ocorre, em grande medida, uma considerável quantidade de produções em matemática que se caracteriza por importantes descobertas de resultados matemáticos interessantes. Entretanto, em que pese a importância dos muitos resultados matemáticos encontrados, eles não são, na maioria das vezes, comprovados por meio de técnicas de demonstrações. E aí surge a questão: se não são comprovados, podem ser considerados conhecimentos da "matemática"? Mais do que isso: se devemos demonstrar os resultados, como isso deve ser feito? 


\section{O DESENLACE FILOSÓFICO}

Os matemáticos, a partir do fim do século XIX, passaram a se questionar sobre as bases fundamentadoras da matemática. Eles focaram suas atenções nas origens de cada teoria, analisando-as e tentando reconstruí-las, para que assim pudessem dar confiabilidade a seus fundamentos. Para se ter noção, até a Lei da Tricotomia ${ }^{17}$ passou por análises rigorosas, pois havia a possibilidade de ela ser falsa, o que poderia comprometer todas as teorias que eram dependentes dela.

Desde os antigos gregos a matemática vem acumulando mais teoremas e verdades, e embora a maioria deles tenha sido rigorosamente provada os matemáticos temiam que alguns casos, como a lei da tricotomia, tivessem sido aceitos sem o exame adequado. Algumas ideias tinham se tornado parte da tradição e ninguém tinha certeza de como foram originalmente demonstradas, se de fato algum dia tinham sido (Singh, 2014, p. 129).

$\mathrm{Na}$ empreitada de demonstrar as diversas teorias e também os seus pilares fundamentais, os matemáticos trabalharam num processo que podemos chamar de retrospecto. Assim, partiam de teoremas já validados e deduziam a partir destes aqueles que ainda não possuíam prova, de modo que, chegando a questões tão elementares, já não era mais possível encontrar uma demonstração. Essas questões elementares são os axiomas das teorias e é a partir deles que a matemática deveria ser reconstruída, segundo Singh (2014).

No propósito de reconstrução da matemática a partir de seus fundamentos, muitos teóricos se uniram - entretanto, nem todos sob uma mesma bandeira. Nesse contexto, emergem três escolas filosóficas: o Logicismo, o Intuicionismo e o Formalismo. Seguindo essa mesma ordem, temos como primeira aparição a doutrina logicista, que tem como seus principais defensores Gottlob Frege (1848-1925), Giuseppe Peano (1858-1932), Bertrand Russel (1872-1970) e Alfred North Whitehead (1861-1947). "Este movimento tinha por objetivo mostrar a matemática como uma

${ }^{17}$ Essa lei diz que um número é negativo, positivo ou nulo. 


\section{Universidade Federal da Grande Dourados}

Ciência consistente e completa e expô-la como uma linguagem simbólica para simplificar suas formas de apresentação" (Mondini, 2008, p. 3-4).

Os princípios desta escola fundamentavam-se na obra Principia Mathematica, cujos autores são Russell e Whitehead. "Na obra buscou-se mostrar que toda matemática clássica poderia ser deduzida da teoria dos conjuntos e, ao final, mostrar que a matemática clássica poderia ser escrita com as peças da lógica" (Batistela et al. 2017, p. 199). Bastava mostrar que a teoria dos conjuntos era pertencente à lógica. Assim,

a tarefa então passou a ser a seguinte: demonstrar que os axiomas do Principia pertenciam à lógica. Como, neste caso, em vez dos axiomas do Principia, poderia se usar qualquer outra teoria formal dos conjuntos, e, a teoria desenvolvida por Zermelo e Frankel (ZF) é mais conhecida (Batistela et al., 2017, p. 199).

A surpresa foi que, analisando o axioma da escolha e o axioma da infinidade, ambos da teoria ZF, conclui-se que eles não poderiam ser inerentes à lógica. De acordo com Batistela et al. (2017), tais axiomas só seriam aceitos como pertencentes à lógica se aceitos em função de seus conteúdos e não de suas formas sintáticas, o que seria contrário à definição de proposições aceitas pelos lógicos. "A escola logicista fracassou devido à impossibilidade de ela própria mostrar concretamente que todas as proposições matemáticas poderiam ser expressas na terminologia lógica e, que todas as proposições matemáticas verdadeiras são as expressões verdadeiras para a lógica" (Batistela et al., 2017, p. 200).

Porém, essa escola filosófica "foi o ponto de partida para o desenvolvimento da lógica matemática moderna e para a formação de um segundo grupo de matemáticos que, contrariamente aos logicistas, procuraram sistematizar a Matemática, partindo, sempre da intuição, os intuicionistas" (Mondini, 2008, p. 5). Esses estudiosos consideravam que a matemática deveria ter suas bases bem seguras e estruturadas a partir da intuição. 
Os intuicionistas consideravam o ser humano dotado de uma intuição primeira sobre os números naturais. Por isso defendiam uma reelaboração da Matemática desde seus fundamentos. Partindo sempre da intuição, os axiomas, os teoremas, enfim, toda a Matemática deveria ser reconstruída. O que fundamentava o movimento intuicionista era a consideração de que as entidades abstratas existiam somente quando eram construídas pela mente humana (Mondini, 2008, p. 5).

Se na efetivação de uma contagem conseguimos esse feito apenas pensando, então "o mesmo que vale para os números vale para as demonstrações, para os teoremas e para as definições" (Batistela et al., 2017, p. 201). De acordo com Batistela et al. (2017), os teoremas e resultados intuicionistas eram muito longos, e por serem assim se tornavam menos elegantes, por perderem a engenhosidade e a brevidade.

Dessa forma, "as consequências mais importantes da definição intuicionista de matemática são: a matemática é construtiva e ela não pode ser reduzida a nenhuma outra ciência" (Batistela et al., 2017, p. 201). Partindo-se desses princípios, os intuicionistas se tornaram contrários aos logicistas, pois, devido a essa definição e na clareza de que para os lógicos as leis eram entendidas como combinações de palavras e não como construções mentais, o que era matemática para um grupo poderia não ser para o outro e vice-versa. Dito de outra forma, tudo o que não atende ao critério não é matemática. Entretanto, o problema é que, para a escola intuicionista, boa parte do conhecimento matemático foi excluído, pois tudo o que não se pautava na intuição não era matemática.

Seguindo a lista de escolas filosóficas, resta ainda falar de um último grupo, o dos formalistas. Como a mais considerável figura frente a essa ideologia estava a de David Hilbert (1862-1943), grande adepto da ideia de que tudo na matemática pode e deve ser provado a partir dos axiomas básicos.

O objetivo principal do formalismo é provar que as ideias matemáticas são isentas de contradições. Caso os formalistas alcançassem seu objetivo, a Matemática se tornaria livre de paradoxos e contradições e, quando ela pudesse ser reescrita com demonstrações rigorosas em um sistema formal, se estabeleceria como verdade (Mondini, 2008, p. 6). 


\section{Universidade Federal da Grande Dourados}

De acordo com Singh (2014), para os formalistas, as teorias já formalizadas estariam livres de inconsistências, pois sendo uma afirmação verdadeira a partir de um método, não poderíamos concluir que ela seja falsa a partir de outro. Porém, em 1931, Gödel demonstra seus dois teoremas da incompletude. Ele mostrou em seus trabalhos $^{18}$ ser impossível criar um sistema matemático que fosse completo e consistente. Os dois teoremas resumem suas ideias:

\section{Primeiro teorema da indecidibilidade}

Se o conjunto axiomático de uma teoria é consistente, então existem teoremas que não podem ser nem provados nem negados.

Segundo teorema da indecidibilidade

Não existe procedimento construtivo que prove ser consistente a teoria axiomática (Singh, 2014, p. 132).

Com a primeira declaração acima, diz-se que, independentemente do conjunto de axiomas que se escolhe em uma teoria, sempre existirão problemas para os quais não há solução. Tal afirmação, segundo Singh (2014), fere diretamente os objetivos de se alcançar a completeza. Já a segunda declaração quer dizer que, não importa qual seja o sistema em que se esteja trabalhando, haverá sempre a incerteza na escolha de axiomas, podendo acontecer de a teoria apresentar contradições. Podemos ainda expor que a segunda afirmação não diz que os sistemas matemáticos são inconsistentes, mas que a demonstração da sua consistência o é. Este fato é suficiente para manter a crença na permanência da consistência da matemática, e de acordo com Mondini (2008), a matemática atual é fruto de todo esse processo de elaboração e reelaboração de si mesma.

\section{CONSIDERAÇÕES FINAIS}

No período em que viveu Euclides, as provas, compreendidas como argumentos, validavam as proposições e assertivas das teorias e compunham parte

18 Gödel publicou o livro intitulado: Sobre as proposições indecidíveis no Principia Mathematica e sistemas relacionados. 
central em produções matemáticas. Já nos períodos das Idades Média e Moderna, dá-se uma interrupção com o desenvolvimento até ali alcançado. Em consequência disso, há o esquecimento metodológico em relação à produção matemática. Mesmo em tempos posteriores, com a presença de teóricos notáveis como I. Newton e R. Descartes, admiradores do método axiomático-dedutivo, não se detectou em suas obras nenhum traço do que vem a ser uma demonstração ou prova.

Somente na modernidade é que os matemáticos passaram a contestar os fundamentos das teorias matemáticas, que nos idos do século XIX haviam se expandido assombrosamente. Isso com a intenção de examinar se, de fato, o que foi produzido e aceito por tantos anos era realmente pertencente à matemática. Entre os estudiosos há o consenso sobre a necessidade de comprovação, porém, há discordância sobre como isso deve ser feito. Colocava-se a atenção sobre as estruturas das provas matemáticas.

Segundo Silva (2002), tais demonstrações podem ser utilizadas. Em primeiro lugar, a argumentação dedutiva deve estabelecer a veracidade relativa à alguma tese enunciada, o que, de certo modo, conduz-nos ao convencimento da verdade teórica. Entretanto, quando consideramos teorias sistematizadas, ou seja, aquelas em que se impõem condições primárias (axiomas), e a partir dessas e das inferências lógicas, deduzem-se todos os resultados subsequentes, podemos ainda destacar outro propósito com o uso de demonstrações, a busca pela consistência.

No desenvolvimento de Os Elementos, Euclides utilizou o método axiomático, o qual ele mesmo desenvolveu. Como exposto ao longo deste trabalho, o modelo dedutivo proposto por ele teve seus momentos de altos e de baixos, tendo sido retomado com veemência principalmente pelos matemáticos formalistas do século XIX. Fato é que, embora a matemática tenha seus desenvolvimentos por meios de testes empíricos, ou pela observação, sua afirmação teórica só se comprova por meio de inferências lógicas de demonstração.

Parece haver momentos em que a matemática passa por uma série de desenvolvimentos, mesmo que sem comprovação dedutiva, e termina após um tempo por ser formalizada. Primeiro se descobre o fato, em seguida ele é demonstrado. 


\section{Universidade Federal da Grande Dourados}

Desde a Idade Média, com o desenrolar de diversas teorias, identificamos a necessidade de comprovação, imposta pelos próprios matemáticos, haja vista que o Cálculo desenvolvido por Newton e Leibniz foram seriamente criticados.

A resposta a essa incessante carência veio sob um enfoque filosófico e idealista, que se constituiu com os movimentos filosóficos do século XIX. A matemática se estrutura principalmente a partir do modo de pensar o formalismo que, na figura de Hilbert, sem dúvidas uma das mais comentadas na literatura, reafirmou o objetivo de formalização da matemática na contemporaneidade, com a intenção de estabelecer uma linguagem formal, e, a partir de demonstrações, livrar a matemática das suas contradições.

\section{AGRADECIMENTOS}

O presente trabalho foi realizado com apoio da Fundação de Amparo à Pesquisa do Estado de São Paulo (FAPESP), processo no 2021/02911-7. 


\section{Universidade Federal da Grande Dourados}

\section{REFERÊNCIAS}

Abbagnano, N. (2007). Dicionário de Filosofia (5a ed., A. Bosi, trad.). São Paulo: Martins Fontes. (Obra original publicada em 1961).

Batistela, R. F., Bicudo, M. A. V., Lazari, H. (2017). Cenário do Surgimento e o Impacto do Teorema da Incompletude de Gödel na Matemática. Jornal Internacional de Estudos em Educação Matemática, 10(3), 198-207.

Bicudo, I. (1999). História da Matemática: o pensamento da filosofia grega antiga e seus reflexos na educação matemática do mundo ocidental. Pesquisa em educação matemática: concepções e perspectivas. São Paulo: Editora da UNESP.

Bicudo, I. (2002). Demonstração em matemática. Bolema - Boletim de Educação Matemática, 15(18), 79-90.

Bicudo, M. A. V. (2012). A pesquisa em educação matemática: a prevalência da abordagem qualitativa. Revista Brasileira de Ensino de Ciência e Tecnologia, 5(2), 15-26.

Bicudo, M. A. V. (2016). Sobre história e historicidade em Edmund Husserl. Cadernos da EMARF, Rio de Janeiro, 9(1), 21-48.

Contador, P. R. M. (2006). Matemática: A história da matemática e das ideias que moldaram o mundo atual desde o início do Renascimento até as bases do cálculo diferencial e integral. Editora Livraria da Física. 
D’ambrosio, U. (2018). Etnomatemática, justiça social e sustentabilidade. Estudos Avançados, São Paulo, 32(94), 189-204.

Domingues, H. H. (2002). A demonstração ao longo dos séculos. Bolema-Boletim de Educação Matemática, 15(18), 55-67.

Euclides. (2009). Os Elementos: Euclides (I. Bicudo, trad.). São Paulo: UNESP.

Eves, H. (2004). Introdução à história da matemática (2a ed.). Campinas: Editora Unicamp.

Filho, D. C. M. (2012). Um convite à Matemática. Rio de Janeiro: Sociedade Brasileira de Matemática.

Gadamer, H. G. (2002a). Verdade e método: traços fundamentais de uma hermenêutica filosófica (4a ed.). Petrópolis: Vozes.

Gadamer, H. G. (2002b). Verdade e método II: complementos e índice (2a ed.). Petrópolis: Vozes.

Garnica, A. V. M. (1995). Fascínio da técnica, declínio da crítica: um estudo sobre a prova rigorosa na formação do professor de matemática (Tese de Doutorado em Educação Matemática). Instituto de Geociências e Ciências Exatas, Universidade Estadual Paulista “Júlio de Mesquita Filho”, Rio Claro, São Paulo, Brasil.

Heidegger, M. (1988). Ser e Tempo (M. S. Cavalcante, trad.). Petrópolis: Vozes.

Mondini, F. (2008). O logicismo, o formalismo e o intuicionismo e seus diferentes modos de pensar a matemática. EBRAPEM, 12, 01-10.

Oliveira, A. J. F (2005). Formalismo hilbertiano vs. pensamento intuitivo. Boletim da Sociedade Portuguesa de matemática, 52(1), 01-25. 


\section{Universidade Federal da Grande Dourados}

Scholtz, G., Pacheco, M. N. C. (1988). Origem e papel das ciências do espírito. Revista da Faculdade de Educação, 14(2), 315-322.

Silva, J. J. (2002). Demonstração Matemática da Perspectiva da Lógica Matemática. Bolema-Boletim de educação matemática, 15(18), 68-78.

Silva, J. J. (2007). Filosofia da matemática (1a ed.). São Paulo: UNESP.

Singh, S. (2014). O último teorema de Fermat. Rio de Janeiro: BestBolso.

\section{CONTRIBUIÇÕES DOS AUTORES}

1a autor: conceitualização; curadoria de dados; análise formal; investigação; metodologia; administração do projeto; visualização; redação - rascunho original; redação - revisão e edição.

$2^{\circ}$ autor: conceitualização; curadoria de dados; análise formal; investigação; metodologia; administração do projeto; supervisão; visualização; redação - rascunho original; redação - revisão e edição. 